\title{
Histological and Immunohistochemical Changes after Transurethral Balloon Laser Hyperthermia in the Canine Prostate
}

\author{
Takanori Suzuki, Kohei Kurokawa, Kazuhiro Suzuki, \\ Kazuhisa Matsumoto and Hidetoshi Yamanaka \\ Department of Urology, Gunma University School of \\ Medicine, Maebashi 371
}

\begin{abstract}
Suzuki, T., Kurokawa, K., Suzuki, Kz., Matsumoto, K. and Yamanaka, H. Histological and Immunohistochemical Changes after Transurethral Balloon Laser Hyperthermia in the Canine Prostate. Tohoku J. Exp. Med., 1995, 177 (1), 39-48 - Transurethral balloon laser hyperthermia (TUBAL-H) for the prostate was performed in a canine model. Eleven normal and hyperplastic prostates were heated at between 40 to $45^{\circ} \mathrm{C}$ for $30 \mathrm{~min}$. Compared to the pretreatment weight, the prostatic weight significantly increased immediately after treatment and significantly decreased at 4 weeks later, but was not significantly different after 8 weeks. Histologically, shedding of epithelial cells was observed immediately after treatment, although, coagulonecrotic tissue was not seen. After 8 weeks, atrophic changes of epithelial cells were observed at the inner portion of the prostate. By immunohistochemical analysis, epithelial cells expressing apoptosis related antigen $\left(\mathrm{Le}^{\mathrm{y}}\right)$ were observed at the inner portion of the prostate from immediately after treatment until 4 weeks later. The atrophic epithelia and the expression of apoptosis in the prostate gland were pathological changes induced by TUBAL-H. From the present data, it is suggested that TUBAL-H combined with radiation or administration of anti-cancer drugs may be effective for prostate cancer. neodymium; YAG; hyperthermia; immunohistochemistry; prostate
\end{abstract}

Recently developed treatments with reduced invasiveness for prostatic diseases include pharmacotherapy for benign prostatic hyperplasia (BPH), such as 5 alpha-reductase inhibitors and alpha blockers, LHRH agonist for prostate cancer and transurethral hyperthermia and thermotherapy for $\mathrm{BPH}$ or prostate cancer (McCullough 1991). Several treatments using lasers have been applied for BPH in attempts to reduce the surgical complications and to improve the patient's symptoms (Roth and Aretz 1991; Kabalin 1993; Suzuki et al. 1994a). The neodymium : YAG (Nd: YAG) laser has been used transurethrally for localized prostate cancer (Sander and Beisland 1984). Prostate cancer is well known to response to estrogen therapy, however that unresponsive to endocrine therapy is

Received February 20, 1995; revision accepted for publication June 15, 1995.

Address for reprints: Dr. Takanori Suzuki, Department of Urology, Gunma University School of Medicine, 3-39-22 Showa-machi, Maebashi, Gunma 371, Japan. 
difficult to manage. It is necessary to develop a new treatment for hormoneunresponsive prostate cancer.

The PROSTALASE ${ }^{\mathrm{TM}}$ system (SLT-Japan, Co., Ltd., Hachioji) generates a transurethral Nd:YAG laser beam delivered to the prostatic tissue in a spindle pattern via an internal laser probe with or without urethral cooling by the intra-balloon circulation of cooled water (Suzuki et al. 1994a). It has been speculated that hyperthermia, thermotherapy or prostatectomy can be performed for various prostatic diseases using this device (Suzuki et al. 1994b). This article is the first report to our knowledge of application of transurethral balloon laser hyperthermia (TUBAL-H) to the prostate in a canine model. The immunohistological changes in the canine prostate after TUBAL- $\mathrm{H}$ are described, and it is suggested that TUBAL-H combined with radiation or anti-cancer drugs is a useful treatment for prostate cancer.

\section{Materials and Methods}

\section{Animal model}

Eleven male mongrel dogs weighing 8 to $15 \mathrm{~kg}$ (mean weight, $11.1 \mathrm{~kg}$ ) were used in the present study. Each dog was given general anesthesia with intramuscular administration of sodium pentobarbital $(25 \mathrm{mg} / \mathrm{kg})$ and atropine sulfate $(0.05 \mathrm{mg} / \mathrm{kg})$ in an intravenous drip of physiological saline solution, and was ventilated with dinitrogen monoxide, oxygen and halothane (Hoechst Japan Ldt., Tokyo) using a mask under spontaneous respiration. A perineal urethrostomy was performed for the insertion of a balloon laser probe prior to TUBAL-H. All dogs were treated according to our Institute's Guide for the Care and Use of Laboratory Animals.

\section{TUBAL-H procedure}

The thermocouple that controls the treatment temperature was inserted into the prostatic tissue to the left of the urethra under transrectal ultrasound guidance (SAL-77B; Toshiba, Tokyo). The tip of the thermocouple was placed $5 \mathrm{~mm}$ or 6 $\mathrm{mm}$ deep to the urethral surface, which location has been found to show a peak temperature during TUBAL-H with urethral cooling in dogs (Suzuki et al. 1994b). The balloon laser probe $(2 \mathrm{~cm}$ length and $3 \mathrm{~mm}$ diameter) was inserted into the prostatic urethra, and the intra-balloon space was circulated with cooled water $\left(10^{\circ} \mathrm{C}\right)$. The diameter of the inflated balloon was $1 \mathrm{~cm}$, and the internal pressure was $0.3 \mathrm{~kg} / \mathrm{cm}^{2}$. The balloon probe has three thermocouples, which were used to measure the temperatures of the bladder neck ( $\mathrm{Tbn})$, the surface of the prostatic urethra (Ts), and the urethral sphincter (Tsp). For measurement of the temperature of the rectum ( $\mathrm{Tr}$ ), a thermocouple was placed transrectally on the ventral

wall of the rectal mucosa. During treatment, the position of the balloon and the thermocouple were observed by transrectal ultrasonography.

TUBAL-H treatment was performed at 30 watts in the intra-balloon per- 
fusion rate range from 10 to $100 \mathrm{ml} / \mathrm{min}($ mean $30 \mathrm{ml} / \mathrm{min})$ to maintain Ts at $40^{\circ} \mathrm{C}$. After the temperature at the depth of $5 \mathrm{~mm}$ from the urethral surface (T5) reached $45^{\circ} \mathrm{C}$, the treatment was continued for $30 \mathrm{~min}$. After treatment, the balloon probe was withdrawn, urination could be performed naturally. A $0.1 \mathrm{ml} / \mathrm{kg}$ bolus of benzylpenicillin (Duopen; Pitman-Moore Ireland Ltd., Bray, Ireland) was administered intramuscularly.

Prostatic lengths and volume were measured using transrectal ultrasonography, and the prostatic weight was calculated using the following equation: Prostatic weight $(\mathrm{g})=0.602 \times$ prostatic volume $\left(\mathrm{cm}^{3}\right)+1.16$ (Berry et al. 1985). Ultrasonic observation was performed before treatment, immediately after treatment, and once each week for the first 16 weeks after treatment.

The histological examination was performed in one dog immediately after treatment, in two at 4 weeks, in two at 8 weeks, and in six at 16 weeks. The prostate was removed and fixed in $20 \%$ buffered formalin, serially sectioned perpendicular to the urethra, and embedded in paraffin. Histological examination was performed after sectioning and staining with hematoxylin and eosin.

Immunohistochemical analysis for proliferating cell nuclear antigen (PCNA) and $L e^{\mathrm{y}}$ antigen

Immunohistochemical staining was performed according to a previously reported technique (Hiraishi et al. 1993). Sections were deparaffinized, incubated in freshly prepared $0.3 \% \mathrm{H}_{2} \mathrm{O}_{2}$ methanol solution for $30 \mathrm{~min}$, and immersed sequentially in ethanol, phosphate-buffered saline (PBS) and 10\% normal goat serum for $30 \mathrm{~min}$. They were then incubated with primary antibody overnight at $4^{\circ} \mathrm{C}$. The primary antibodies used were anti-PCNA mouse monoclonal antibody (Dako, Copenhagen, Denmark) and anti-Le ${ }^{\mathrm{y}}$ mouse monoclonal antibody (BM1/ JIMRO, Japan Immunoresearch Lab. Co., Ltd., Takasaki). Sections were washed with PBS and incubated with secondary antibodies for $1 \mathrm{hr}$ at room temperature. The secondary antibodies used were biotinylated goat anti-mouse IgG antibody (Vectastain ABC Kit; Vector, Burlingame, CA, USA) for PCNA and biotinylated goat anti-mouse IgM antibody (Vectastain ABC Kit; Vector) for $\mathrm{Le}^{\mathrm{y}}$. Sections were washed with $\mathrm{PBS}$, treated with $\mathrm{ABC}$ complex for $30 \mathrm{~min}$, and washed with PBS. They were submerged in $0.05 \%$ diaminobenzidine tetrahydrochloride in $0.05 \mathrm{M}$ Tris-buffer ( $\mathrm{pH} 7.6$ ) to which $\mathrm{H}_{2} \mathrm{O}_{2}(0.01 \%$ ) had been added just before use. Counterstaining was performed with methyl green. The specificity of staining reaction was confirmed in sections treated with omission of the primary antibody from the procedure. As a control for treated prostates, five normal and intact prostate (prostatic weight; less than $10 \mathrm{~g}$ ) were stained using a similar procedure described above.

Statistical analysis was performed using Wilcoxon's matched-pairs test, and a significant difference was accepted when the $p$ value was less than 0.05 . 


\section{RESULTS}

Change in the tissue temperature during treatment

The course of change in the tissue temperature during treatment is shown in Fig. 1. T5 reached the target temperature for treatment at $45 \mathrm{sec}$ (range, 30 to 50 sec) and was constant thereafter at $45^{\circ} \mathrm{C}$. Ts ranged from 39 to $44^{\circ} \mathrm{C}$ (mean, $\left.41.8^{\circ} \mathrm{C}\right)$, Tbn from 39 to $43^{\circ} \mathrm{C}\left(41^{\circ} \mathrm{C}\right)$, Tsp from 38 to $40^{\circ} \mathrm{C}\left(39^{\circ} \mathrm{C}\right)$, and $\operatorname{Tr}$ from 38 to $41.5^{\circ} \mathrm{C}\left(40^{\circ} \mathrm{C}\right)$. The change of each temperature was slight without the movement of the transrectal probe. The total energy was 13,629 to $32,187 \mathrm{~J}$ (mean, $25,128.5 \mathrm{~J})$.

Changes of the prostatic weight after treatment

The prostatic weight was $6.2 \pm 4.4 \mathrm{~g}$ (means \pm s.D.) (range, 2.8 to $18.3 \mathrm{~g}$ ) before treatment, and was significantly increased to $9.4 \pm 5.0 \mathrm{~g}$ (5.3 to $22.5 \mathrm{~g}$ ) immediately after treatment $(p<0.01)$. After 4 weeks, it significantly decreased to $4.7 \pm 2.6 \mathrm{~g}$ (2.3 to $11.2 \mathrm{~g})$ compared with that before treatment $(p<0.05)$. The prostatic weight was $4.7 \pm 2.0 \mathrm{~g}$ at 8 weeks, $4.5 \pm 2.2 \mathrm{~g}$ at 12 weeks, and $5.5 \pm 2.8 \mathrm{~g}$ at 16 weeks. The weight at 8 to 16 weeks was lower than that before treatment, but this difference was not significant (Fig. 2).

\section{Histological and immunohistochemical findings}

Histologically, nine prostates showed normal tissue type, one normal and hyperplastic type, and one hyperplastic type. No cavity formation was macroscopically observed in any dog.

Normal and intact prostates had no positive immunoreaction for $\mathrm{Le}^{\mathrm{y}}$ antigen. A few PCNA-positive cells were seen in the epithelium of the prostate.

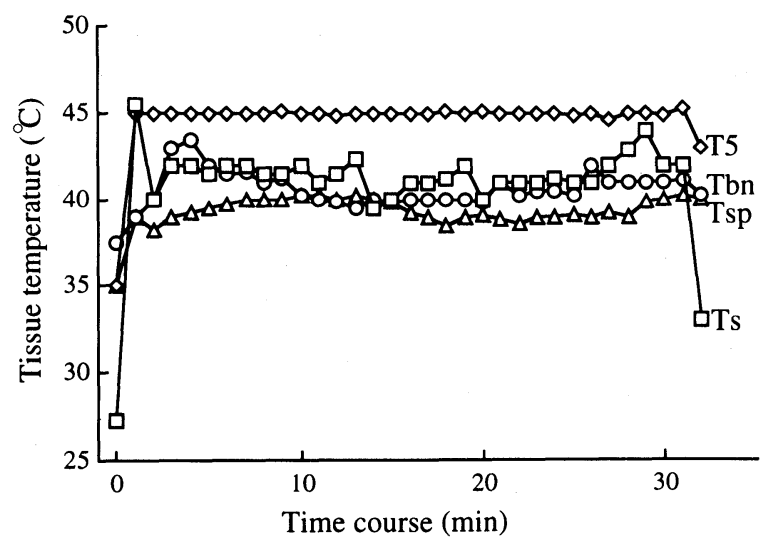

Fig. 1. Changes of the tissue temperature during treatment. Ts, the temperature of urethral surface; Tbn, the temperature of bladder neck; Tsp, the temperature of urethral sphincter; T5, the temperature at the depth of $5 \mathrm{~mm}$ from the urethral surface. 


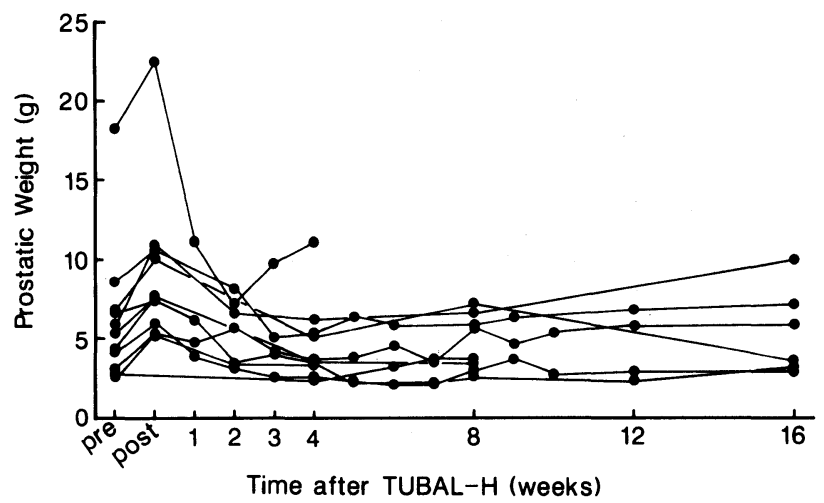

Fig. 2. The course of changes of the prostatic weight in each dog after transurethral balloon laser hyperthermia (TUBAL-H).

Immediately after treatment, no coagulation necrosis was observed in the prostatic tissue containing glandular and stromal tissues. Partial shedding of epithelial cells was found in the lumen at the inner portion of the prostate gland (Fig. 3). There was slight edema of the stroma, although there was no thrombocytic thrombus of vessels or swelling of collagen fibers. PCNA-positive epithelial cells were not observed in the prostate in this study. Le $\mathrm{Le}^{\mathrm{y}}$-positive cells were observed in the epithelium in several ducts and acini, and were localized mainly in the inner portion of the prostate (Fig. 4). The stromal cells were $\mathrm{Le}^{\mathrm{y}}$ negative. There was no tissue damage of the urethral mucosa other than partial transitional cell detachment.

At 4 weeks, invasion of inflammatory cells into the stroma and atrophic

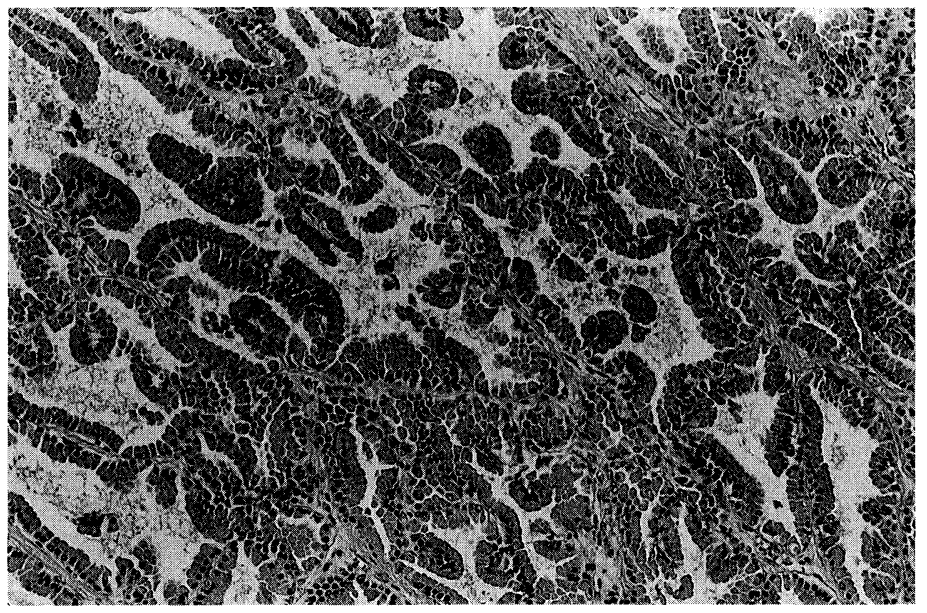

Fig. 3. Photomicrograph of the prostate gland immediately after treatment. Shedding of glandular epithelial cells in the lumen is observed but coagulation necrosis is not seen. Hematoxylin and eosin staining, $\times 100$. 


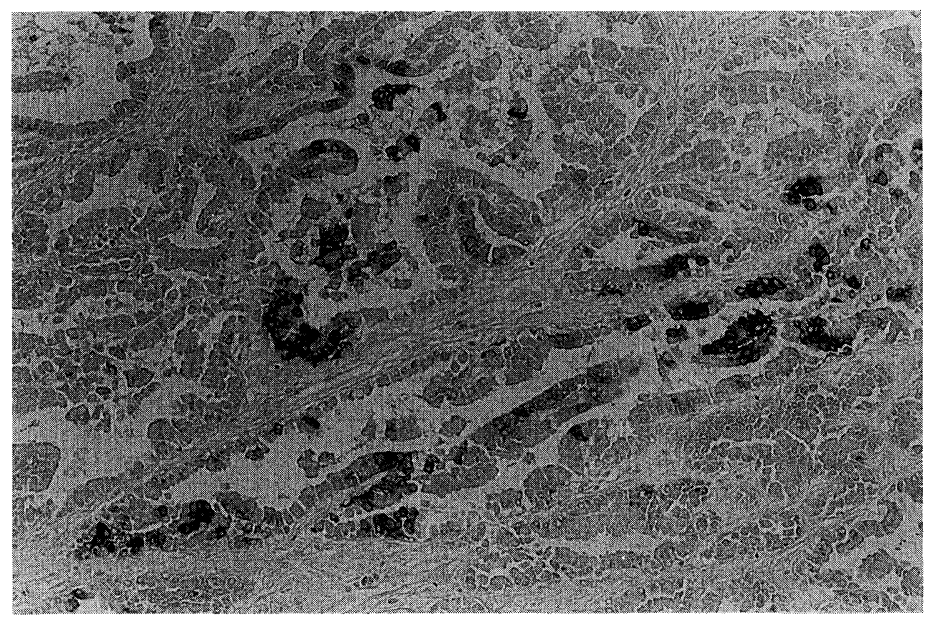

Fig. 4. Photomicrograph of immunostaining for $\mathrm{Le}^{\mathrm{y}}$ immediately after treatment. Several epithelial cells of the prostate gland show positive immunostaining for $\mathrm{Le}^{\mathrm{y}}$. $\mathrm{Le}^{\mathrm{y}}$ immunoreaction was localized at the cell membrane of prostatic epithelia. Methyl green counterstaining, $\times 100$.

epithelial cells were observed in some parts of the inner area. Most epithelial cells showed no findings of tissue damage such as shedding of epithelial cells or nuclear changes. While only a few PCNA-positive cells were seen in the epithelium, many epithelial cells of the prostate showed relatively strong immunoreaction for $\mathrm{Le}^{\mathrm{y}}$. Le $\mathrm{Le}^{\mathrm{y}}$-positive cells were localized mainly at the inner portion of the prostate gland.

At 8 to 16 weeks, atrophic epithelial cells of ducts and acini were observed at

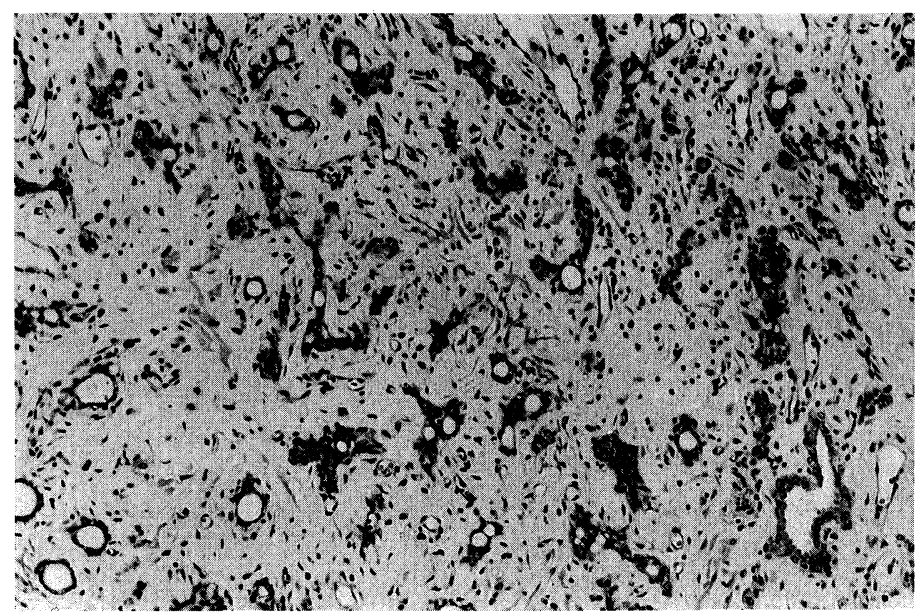

Fig. 5. Photomicrograph of the prostate at the inner portion at 16 weeks. The epithelial cells of the prostae are atrophic, and several glands show dilatation of acini. Hematoxylin and eosin staining, $\times 100$. 


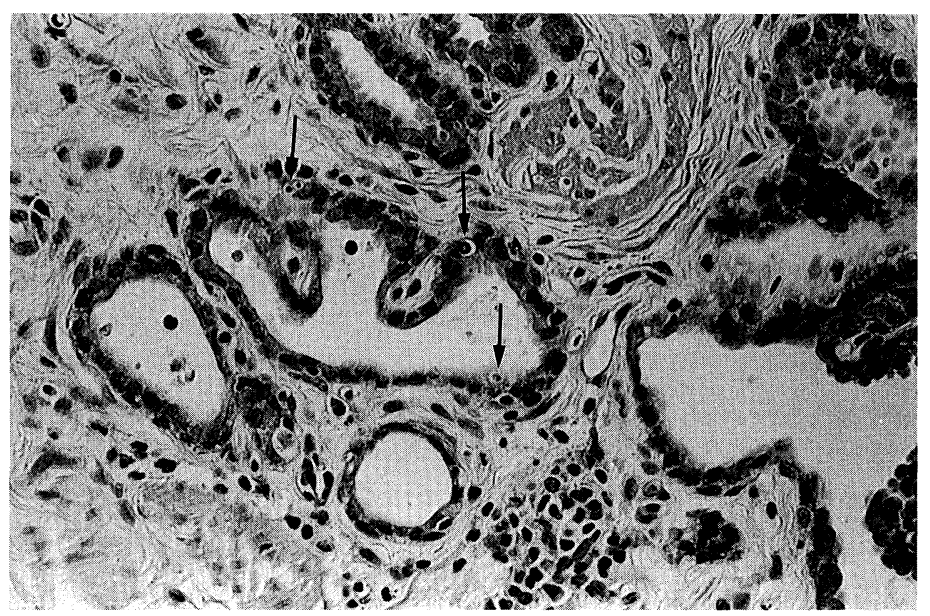

Fig. 6. Photomicrograph of the prostate at 8 weeks. Glandular epithelial cells are atrophic, and some of them have a condensed nucleus (arrows). Hematoxylin and eosin staining, $\times 350$.

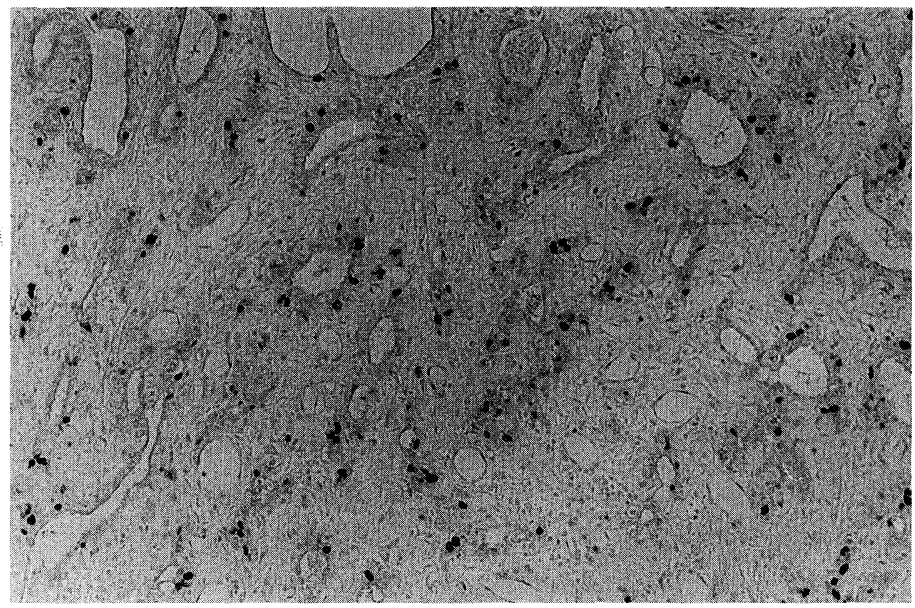

Fig. 7. Photomicrograph showing immunostaining for PCNA at 16 weeks. The epithelial cells show atrophic change, and many nuclei of epithelial and stromal cells show positive immunostaining for PCNA. Methol green counterstaining, $\times 100$.

the inner portion of the prostate, at the depth of 5 to $6 \mathrm{~mm}$. from the urethral surface (Fig. 5). Condensed epithelial cell nuclei were found in the ducts and acini starting to show atrophic change (Fig. 6). The epithelial cells at the outer area showed no histological change. The invasion of inflammatory cells into the stroma was slight and there was no increase of collagen fibers. PCNA-positive cells were observed in the epithelial cells at both the inner and outer portions of the prostate (Fig. 7). Le Le $^{\mathrm{y}}$-positive cells were not observed among the epithelial 
cells of the prostate at this time.

\section{Discussion}

Hyperthermia is considered to be a minimally invasive therapy for BPH and prostate cancer. Microwave and radiofrequency heating devices have been applied in many experimental and clinical cases (Servadio and Leib 1984; Leib et al. 1986; Sapozink et al. 1990; Vanden Bossche et al. 1991; Montorsi et al. 1992). Based on experimental and clinical data, hyperthermia has been concluded to have intrinsic tumoricidal potential, and tumor cells have been demonstrated to be much more sensitive to heat than are normal cells. Since tumor tissue is poorly vascularized and its temperature during hyperthermia is greater than that of the surrounding normal tissue, hyperthermia were combined with radiation or anticancer drugs provides enhanced therapeutic effects (Servadio and Leib 1984; Montorsi et al. 1992).

The histological damage in hyperthermia for the normal and hyperplastic canine prostate has been reported to be minimal or limited only to invasion of inflammatory cells in the stroma (Leib et al. 1986). The application of hyperthermia using low-power Nd: YAG laser for malignant tumors has been reported (Huang et al. 1991). The device used in the present study generates a Nd: YAG laser beam in a spindle pattern from the internal laser fiber through the balloon surface, and heats the prostate gland to a temperature below $45^{\circ} \mathrm{C}$ when combined with urethral cooling (Suzuki et al. 1994b). The pathological changes in laser hyperthermia for the prostate have not been reported, and the present study was conducted to investigate the pathological effects using immunohistochemical analysis.

Coagulation necrosis of the prostate is not observed in the treatment at temperatures below $45^{\circ} \mathrm{C}$ for $30 \mathrm{~min}$ (Devonec et al. 1991; Suzuki et al. 1994b). In the present study, the prostate was heated to between 40 and $45^{\circ} \mathrm{C}$ for $30 \mathrm{~min}$, and no coagulonecrotic tissue or cavity formation in the prostate was observed. However, after treatment, atrophic changes of the prostatic epithelia developed at the inner area of the prostate gland. Roth and Aretz (1991) treated canine BPH by TULIP procedure and found that epithelial cells in the residual glandular tissue, which was irradiated with a Nd : YAG laser, showed atrophic changes at 11 weeks after treatment. No atrophic change of glandular epithelial cells in the canine prostate was observed after hyperthermia using microwaves (Leib et al. 1986). The cause of the atrophy in the present study is unclear, although it has been reported that the mitochondria are the primary target in the cellular damage induced by laser hyperthermia while the activation of lysosomes is the primary target in other hyperthermia technique (Overgaard 1976; Tsunekawa 1990). Due to the difference of the primary target, laser hyperthermia is thought to have not only heat and photo-chemical effects on the prostatic tissue but also to induce the atrophic change of the epithelial cell. 
Recently, hyperthermia has been reported to induce apoptosis in normal and malignant cells (Sellins and Cohen 1991; Takano et al. 1991). Apoptosis (programmed cell death) is characterized morphologically by shrinkage of cytoplasm, condensation and fragmentation of nuclei, membrane blebbing and DNA fragmentation. When apoptosis occurs, the glycosylation of the cell surface shows specific change, and the expression of $\mathrm{Le}^{\mathrm{y}}$ antigen is observed (Hiraishi et al. 1993). In our study immunohistochemical staining for $\mathrm{Le}^{\mathrm{y}}$ antigen revealed $\mathrm{Le}^{\mathrm{y}}$-positive cells at the inner portion of the prostate immediately after treatment and 4 weeks later. These cells showed negative immunostaining for PCNA, which is an indicator of cell proliferation. In the intact prostate, a few PCNA-positive cells were seen in the epithelium, however $\mathrm{Le}^{\mathrm{y}}$-positive cells were not observed. The expression of $\mathrm{Le}^{\mathrm{y}}$ antigen in the epithelial cells was not associated with cell proliferation and is thought to have been induced by laser hyperthermia. Furthermore, some epithelial cells with condensed nuclei were identified in the ducts and acini which had began to show atrophic change of glandular cells. After 8 weeks, Le ${ }^{y}$-positive epithelial cells were very few, and the number of PCNA-positive cells was similar to that in the intact prostate (data not shown). Moreover, the prostatic weight after 8 weeks was not significantly different from that before treatment. These data indicate that the decrease of prostatic weight induced by TUBAL-H is observed for only a short period.

The present study demonstrated that change of glycosylation in the cell surface was induced in the prostate gland by TUBAL-H, and that apoptosis and atrophic change of epithelial cells occurred after this change. These results suggest that TUBAL-H, if that is combined with radiation (Warters 1992), anti-cancer drugs or photodynamic therapy, may be effective in the treatment of localized prostate cancer.

\section{Acknowledgment}

We acknowledge Miss C. Ohma for her technical assistance with the histological studies.

\section{References}

1) Berry, S.J., Sterner, R., Coffey, D.S. \& Ewing, L.L. (1985) Methods for monitoring canine prostate size: Internal and external caliper measurements. Prostate, 6, 303314.

2) Devonec, M., Berger, N. \& Perrin, P. (1991) Transurethral microwave heating of the prostate-or from hyperthermia to thermotherapy. J. Endourol., 5, 129-135.

3) Hiraishi, K., Suzuki, K., Hakomori, S. \& Adachi, M. (1993) Le Le $^{y}$ antigen expression is correlated with apoptosis (programmed cell death). Glycobiology, 3, 381-390.

4) Huang, G.T., Wang, T.H., Sheu, J.C., Daikuzono, N., Sung, J.L., Wu, M.Z. \& Chen, D.S. (1991) Low-power laserthermia for the treatment of small hepatocellular carcinoma. Eur. J. Cancer, 27, 1622-1627.

5) Kabalin, J.N. (1993) Laser prostatectomy performed with a right angle firing neodymium: YAG laser fiber at 40 watts power setting. J. Urol., 150, 95-99.

6) Leib, Z., Rothem, A., Lev, A. \& Servadio, C. (1986) Histopathalogical observations 
in the canine prostate treated by local microwave hyperthermia. Prostate, 8, 93-102.

7) McCullough, D.L. (1991) This month in investigative urology: Transurethral laser treatment of benign prostatic hyperplasia. J. Urol., 146, 1126-1127.

8) Montorsi, F., Buazzoni, G., Colombo, R., Galli, L., Bergamaschi, F. \& Rigatti, P. (1992) Transrectal microwave hyperthermia for advanced prostate cancer: Longterm clinical results. J. Urol., 148, 342-345.

9) Overgaard, J. (1976) Ultrastructure of a murine mammary carcinoma exposed to hyperthermia in vivo. Cancer Res., 36, 983-995.

10) Roth, R.A. \& Aretz, H.T. (1991) Transurethral ultrasound-guided laser-induced prostatectomy (TULIP procedure): A canine prostate feasibility study. J. Urol., 146, 1128-1135.

11) Sander, S. \& Beisland, H.O. (1984) Laser in the treatment of localized prostatic carcinoma. J. Urol., 132, 280-281.

12) Sapozink, M.D., Boyd, S.D., Astrahan, M.A., Jozsef, G. \& Petrovich, Z. (1990) Transurethral hyperthermia for benign prostatic hyperplasia: Preliminary clinical results. J. Urol., 143, 944-950.

13) Sellins, K. \& Cohen, J.J. (1991) Hyperthermia induces apoptosis in thymocytes. Radiat. Res., 126, 88-95.

14) Servadio, C. \& Leib, Z. (1984) Hyperthermia in the treatment of prostate cancer. Prostate, 5, 205-211.

15) Suzuki, T., Kurokawa, K., Suzuki, Kz., Nakazato, H., Imai, K. \& Yamanaka, H. (1994a) In vivo effects of transurethral balloon laser prostatectomy on the canine prostate. J. Urol., 151, 1092-1095.

16) Suzuki, T., Kurokawa, K., Suzuki, Kz. \& Yamanaka, H. (1994b) Experimental research of transurethral balloon laser therapy for prostatic diseases. Jpn. J. Hyperthermic Oncol., 10, 121-125. (in Japanese)

17) Takano, Y.S., Harmon, B.V. \& Kerr, J.F.R. (1991) Apoptosis induced by mild hyperthermia in human and murine tumour cell lines: A study using electron microscopy and DNA gel electrophoresis. J. Pathol., 163, 329-336.

18) Tsunekawa, H. (1990) Basic and clinical studies on contact method and laserthermia (laser hyperthermia) using Nd: YAG laser. J. Jpn. Soc. Laser Med., 11, 31-40. (in Japanese)

19) Vanden Bossche, M., Noel, J.C. \& Schulman, C.C. (1991) Transurethral hyperthermia for benign prostatic hypertrophy. World J. Urol., 9, 2-6.

20) Warters, R.L. (1992) Radiation-induced apoptosis in a murine T-cell hybridoma. Cancer Res., 52, 883-890. 